\title{
Vitamin A status does not influence neopterin production during illness or health in South African children
}

\author{
Suzanne M. Filteau ${ }^{1,2} *$, John G. Raynes ${ }^{2}$, Karin Simmank $^{3}$ and Lucy A. Wagstaff ${ }^{3}$ \\ ${ }^{1}$ Centre for International Child Health, Institute of Child Health, London WCIN 1EH, UK \\ ${ }^{2}$ Department of Clinical Sciences, London School of Hygiene and Tropical Medicine, London WC1E 4HT, UK \\ ${ }^{3}$ Department of Community Pediatrics, Baragwanath Hospital, University of Witwatersrand, Soweto, \\ PO Bertsham 2013, South Africa
}

(Received 24 September 1997 - Revised 19 January 1998 - Accepted 30 January 1998)

\begin{abstract}
Excessive interferon-gamma (IFN- $\gamma$ ) production appears to be a primary immunological lesion in vitamin A-deficient experimental animals but comparable data from humans is lacking. We investigated IFN- $\gamma$ production in South African children by measurement of urinary excretion of neopterin, a product of IFN- $\gamma$-activated monocytes or macrophages. Preschool children were examined during an acute inflammatory illness resulting from accidental ingestion of kerosene and they and a neighbourhood control child were examined 3 months later when well. Vitamin A status was assessed by the modified relative dose response (MRDR) test at 3 months and serum retinol and acute phase proteins were measured at both time points. Urinary neopterin was measured for forty cases in hospital, forty-six cases after recovery, and forty-one controls. Significantly increased neopterin excretion was seen following kerosene ingestion and in association with raised serum acute phase protein concentrations. There was no relationship between neopterin excretion at either time point and vitamin A status as assessed by MRDR test. Urinary neopterin was negatively correlated with serum retinol but no significant relationship was observed when acute phase protein concentrations were included in a multiple regression, suggesting the correlation was secondary to illness-induced changes in serum retinol. The results indicate that, contrary to what is observed in rodents under experimental conditions, poor vitamin A status is not associated with altered regulation of IFN- $\gamma$ production in children.
\end{abstract}

Vitamin A: Neopterin: Interferon: Childhood

Community vitamin A supplementation trials have clearly shown the importance of adequate vitamin A status for resistance to infectious diseases (Beaton et al. 1993). Studies of the mechanisms of the beneficial effects of vitamin A on resistance to infection have been, for logistical reasons, largely conducted using animal or cell culture models. The general consensus is that two main mechanisms are involved: maintenance of epithelial integrity and promotion of immune functions (Ross \& Stephensen, 1996). However, there remain unanswered questions regarding both of these mechanisms, for example, the exact nature of the immunological defect, and the reason for the greatest benefits of vitamin A being seen for diarrhoea whereas histological evidence indicates the gastrointestinal epithelium is relatively insensitive to vitamin A deficiency (Wolbach \& Howe, 1925; Zile et al. 1981).

Regarding immunological defects, recent studies from several groups have indicated that altered regulation of interferon (IFN) production may be a primary lesion in vitamin A deficiency. Spleen and mesenteric lymph node cells from vitamin A-deficient mice (Carmen et al. 1992; Cantorna et al. 1994) and rats (Wiedermann et al. 1993, 1996) exhibited excessive IFN- $\gamma$ production in response to polyclonal or specific antigen stimulation; however, decreased concanavalin A-stimulated spleen cell production of IFN (Bowman et al. 1990) and normal plasma IFN titres (Zhao et al. 1994) have also been reported in vitamin A-deficient rats. Vitamin A-deficient mice exhibited constitutive transcription and secretion of IFN- $\gamma$ which could be reduced to normal by in vivo retinoic acid supplementation (Cantorna et al. 1995). Retinoic acid also decreased expression of the IFN- $\gamma$ gene in human peripheral blood $\mathrm{T}$ cells in vitro (Cippitelli et al. 1996). However, data on the effects of vitamin A status on IFN- $\gamma$ production in humans is lacking and it is notable that in all the in vitro studies, cultures were adjusted to equal cell numbers, obliterating information about total IFN- $\gamma$ production in vivo. Thus, the resemblance of the various animal and cell culture models to human immune function in vivo remains to be determined. 
Measurement of in vivo cytokine production in normal clinical conditions is difficult due to the short biological half lives of many cytokines making time of sampling critical, the presence of cytokine inhibitors in the samples, and problems of storage (Whiteside, 1994). Recent work has indicated, however, that neopterin, a product of activated macrophages, in urine or serum can be used as a measure of the degree of activation of macrophages by IFN- $\gamma$, produced largely by $\mathrm{T}$ cells (Fuchs et al. 1992). Production of neopterin in vitro is abolished by antibodies to IFN- $\gamma$ (Huber et al. 1984). Neopterin assessment has been found useful for monitoring infections, cancers, organ transplants, and various inflammatory disorders (Fuchs et al. 1992; Iwagaki et al. 1995). Neopterin is produced relatively early in response to infection, is quantitatively excreted in urine and is stable in frozen samples (Fuchs et al. 1992). Therefore, we have used urine samples collected as part of a study of the effect of acute kerosene-induced respiratory inflammation on vitamin A metabolism and status of South African children to examine the effect of vitamin A status on neopterin production during both illness and health. Although kerosene ingestion induces a fairly 'sterile' inflammation, it induces acute phase protein changes and alterations in retinol distribution similar to those found in infection (Willumsen et al. 1997).

\section{Experimental methods}

Study design

Children aged 1 to 5 years, presented at Baragwanath Hospital, Soweto, following accidental kerosene ingestion, a common and serious cause of childhood poisoning in South Africa (De Wet et al. 1994), and who required hospitalization at least overnight, were eligible for the study. The study was approved by the ethical review committees of the University of Witwatersrand, Johannesburg, and the Institute of Child Health, London. Informed consent was obtained and, in addition to standard clinical care, blood samples were taken at admission and the following morning for measurement of serum retinol and the acute phase proteins, $\alpha_{1}$-acid glycoprotein (AGP) and $\mathrm{C}$-reactive protein (CRP). Urine samples were collected the following morning for measurement of retinol binding protein and these were later used for neopterin measurement. Children were followed up fortnightly in the community for 3 months at which time they and an apparently healthy neighbourhood control child of similar age came to the hospital for clinical examination, a modified relative dose response (MRDR) test of vitamin A status and further urine collection. Further details of the study may be obtained from Willumsen et al. (1997). Neopterin assays were performed only for the children who completed the follow-up and for whom MRDR tests of vitamin A stores were available, that is, forty-six of the original fifty-seven case children and forty-one control children. There was insufficient urine for neopterin analysis for hospital samples from six of the forty-six case children.

\section{Laboratory analyses}

Urinary neopterin was measured using a commercial ELISA kit (Brahms Diagnostica, Berlin, Germany) and expressed per mmol of creatinine, measured by the Jaffe method. Analytical procedures for retinol by HPLC (Filteau et al. 1993), 3,4didehydroretinol for the MRDR test (Tanumihardjo et al. 1996; Willumsen et al. 1997), and AGP (Filteau et al. 1994) and CRP (Gillespie et al. 1991) by ELISA have been described previously. The upper limit for AGP concentration in healthy children was taken to be $0.75 \mathrm{~g} / \mathrm{l}$ (Filteau et al. 1994).

\section{Statistical analyses}

Statistical analyses were conducted using SPSS/PC (SPSS Inc., Chicago, IL, USA). Neopterin and other biochemical results were logarithmically transformed to normalize distributions; therefore, results presented are geometric means with $95 \% \mathrm{CI}$ and correlations are between logarithmic values. Neopterin values were compared between groups at 3 months using the Mann-Whitney non-parametric test and between case children at the two time points using the Wilcoxon signed rank test (Kirkwood, 1988). Multiple regressions were conducted to determine factors influencing neopterin production, including age, anthropometry, illness as defined by acute phase protein concentrations, and whether samples were from children in hospital or 3 months later, and vitamin A status as defined by MRDR test results. Since there was no effect of kerosene ingestion on MRDR test results at 3 months (Willumsen et al. 1997), it appeared that the illness, in spite of lowering serum retinol and increasing urinary retinol binding protein excretion acutely, did not significantly affect vitamin A status in the longer term; therefore, MRDR test results at 3 months were considered to indicate vitamin A status at both time points.

\section{Results}

Selected descriptive, nutritional, and acute phase protein data from the subset of children for whom neopterin was measured are shown in Table 1. Further details of vitamin A metabolism and morbidity of the children can be found in Willumsen et al. (1997).

Urinary neopterin excretion was increased when the children were sick after kerosene ingestion but there was no lingering effect of this illness 3 months later, as concentration then did not differ from controls (Table 2). At 3 months, neopterin excretion correlated with CRP $(r 0 \cdot 25$, $P=0 \cdot 024, n 84)$ but not AGP $(r 0 \cdot 17, P=0 \cdot 13, n 84)$. The lack of correlation between neopterin and either acute phase proteins or duration of hospital stay (used as an indicator of illness severity) at the first time point may have been due to the lower sample size at this time. Similarly, there were no correlations at 3 months within case or control groups considered separately. At both time points there was a negative correlation of neopterin with age (in months, at the initial home visit 2 weeks post admission), as has been observed previously (Fuchs et al. 1992) and no significant correlations with haemoglobin or weight for age or height for age $\mathrm{Z}$ scores (data not shown). Although the samples in hospital were all taken in the morning and thus at various times after kerosene ingestion, the time post-ingestion had no significant effect on neopterin excretion.

Neopterin production at both time points was not influenced 
Table 1. Description of control children and cases who ingested kerosene*

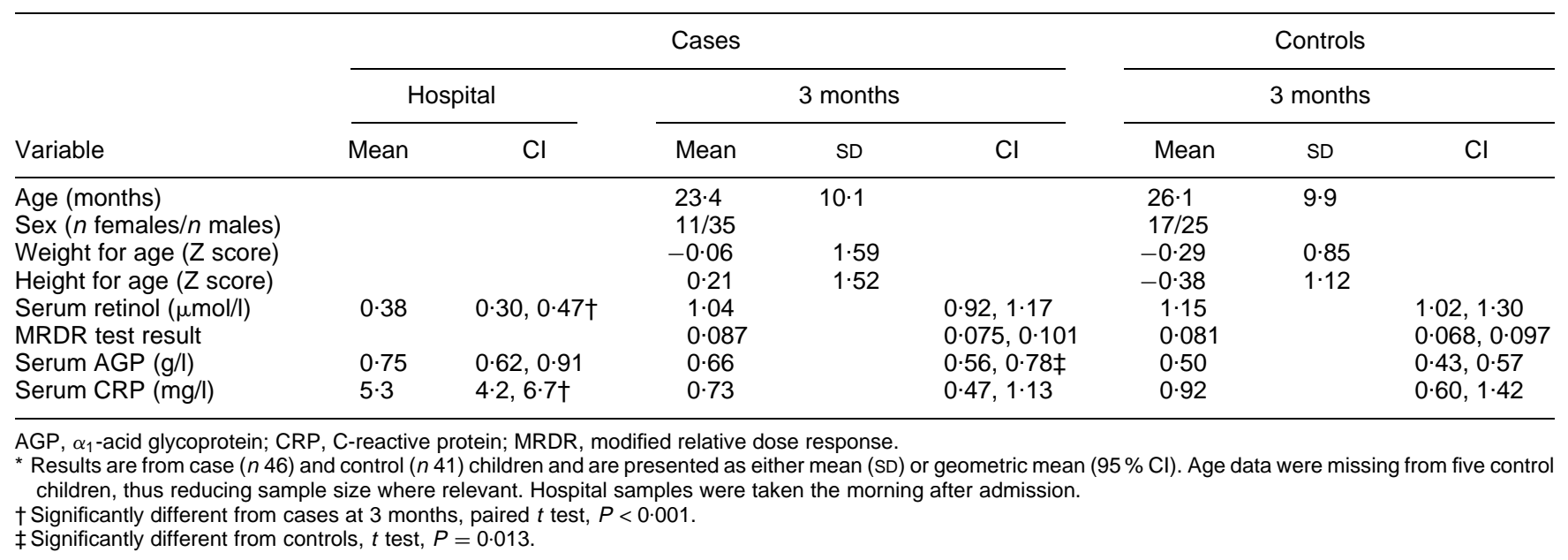

by vitamin A status assessed by whether children had normal (MRDR $\leq 0.06$ ) or abnormal (MRDR $>0.06)$ vitamin A stores (Table 3). Similarly, MRDR test results expressed as a continuous variable were not correlated with urinary neopterin in hospital $(r 0 \cdot 10, P=0 \cdot 54, n$ $40)$, or 3 months later $(r 0 \cdot 06, P=0 \cdot 59, n 86)$. There was a wide range of serum retinol values at admission (0.07$1 \cdot 60 \mu \mathrm{mol} / \mathrm{l})$ and 3 months later $(0 \cdot 45-2 \cdot 79 \mu \mathrm{mol} / \mathrm{l})$. Neopterin excretion correlated with serum retinol during hospitalization $(r-0.33, P=0.046, n 37)$ and at 3 months $(r-0 \cdot 25, P=0 \cdot 022, n 87)$. When multiple regressions were run to determine factors influencing neopterin excretion, only age entered the equation at $5 \%$ significance at both time points, explaining $15.9 \%$ of the variability in neopterin excretion during hospitalization and 7.6\% 3 months later. The only other dependent variable which reached $5 \%$ significance in the multiple regression was CRP at 3 months which explained $8.7 \%$ of the variability in neopterin. Retinol and acute phase proteins were all highly intercorrelated and it appeared that the significant bivariate association between serum retinol and urinary neopterin was secondary to acute phase changes in the former. This conclusion is supported by Fig. 1, in which the relationship between serum retinol and neopterin excretion at 3 months is illustrated with data subdivided according to whether children at that time had normal $(\leq 0.75 \mathrm{~g} / \mathrm{l})$ or raised serum AGP concentrations.

Table 2. Urinary neopterin excretion by South African children in hospital after kerosene ingestion or 3 months later*

\begin{tabular}{lccc}
\hline & & \multicolumn{2}{c}{$\begin{array}{c}\text { Urine neopterin } \\
\text { (nmol/mmol creatinine) } \dagger\end{array}$} \\
\cline { 3 - 4 } & $n$ & Mean & $\mathrm{Cl}$ \\
\hline Cases, hospital & 40 & 1055 & 913,1193 \\
Cases, 3 months & 46 & 646 & 553,754 \\
Controls, 3 months & 41 & 617 & 506,752 \\
\hline
\end{tabular}

* Values are geometric means and $95 \% \mathrm{Cl}$.

† Urinary neopterin during hospitalization was significantly different from 3

months later, Wilcoxon signed rank test, Z 4.17, $P<0 \cdot 0001, n 40$, but there was no difference between cases and controls at the 3-month follow-up, Mann-Whitney $\mathrm{U}$ test $901, P=0.72$.
AGP, rather than CRP, was used since only eight children had raised CRP (>5 mg/l) at this time. The correlation was significant only for children with the raised AGP levels characteristic of an acute phase response.

\section{Discussion}

The present results indicate that in children, unlike in rodents studied in several laboratories, IFN- $\gamma$ production is not affected by vitamin A status either when children are well or when they are sick, that is, during hospitalization or whenever acute phase protein levels are raised. The correlation between neopterin excretion and serum retinol vanished when acute phase proteins were accounted for, indicating that the relationship resulted from the well-documented redistribution of retinol away from plasma during acute phase responses (Ramsden et al. 1978; Rosales et al. 1996; Willumsen et al. 1997).

The biological significance of our neopterin results is supported by the significant difference between production in hospital and 3 months later when children were well and by the correlations with serum acute phase proteins. The conclusions regarding vitamin A status are also strengthened by the fact the study was conducted in a population of

Table 3. Effect of vitamin A stores on urinary neopterin excretion by South African children in hospital after kerosene ingestion and 3 months later*

\begin{tabular}{|c|c|c|c|c|c|c|}
\hline & \multicolumn{6}{|c|}{ Urine neopterin (nmol/mmol creatinine) } \\
\hline & \multicolumn{3}{|c|}{$\begin{array}{l}\text { MRDR } \leq 0.06 \\
\text { (normal stores) }\end{array}$} & \multicolumn{3}{|c|}{$\begin{array}{l}\text { MRDR }>0.06 \\
\quad \text { (deficient) }\end{array}$} \\
\hline & Mean & $\mathrm{Cl}$ & $n$ & Mean & $\mathrm{Cl}$ & $n$ \\
\hline $\begin{array}{l}\text { Hospital } \\
3 \text { months }\end{array}$ & $\begin{array}{r}1059 \\
682\end{array}$ & $\begin{array}{l}763,1469 \\
514,904\end{array}$ & $\begin{array}{r}9 \\
22\end{array}$ & $\begin{array}{r}1054 \\
592\end{array}$ & $\begin{array}{l}896,1240 \\
516,679\end{array}$ & $\begin{array}{l}31 \\
65\end{array}$ \\
\hline
\end{tabular}

MRDR, modified relative dose response test result.

*Values are geometric means $(95 \% \mathrm{Cl}, n)$. Urinary neopterin was not different by Mann-Whitney non-parametric test between children with adequate or deficient vitamin A stores either when in hospital, $U 132, P=0.81$, or 3 months later, $\cup 681, P=0 \cdot 74$. 

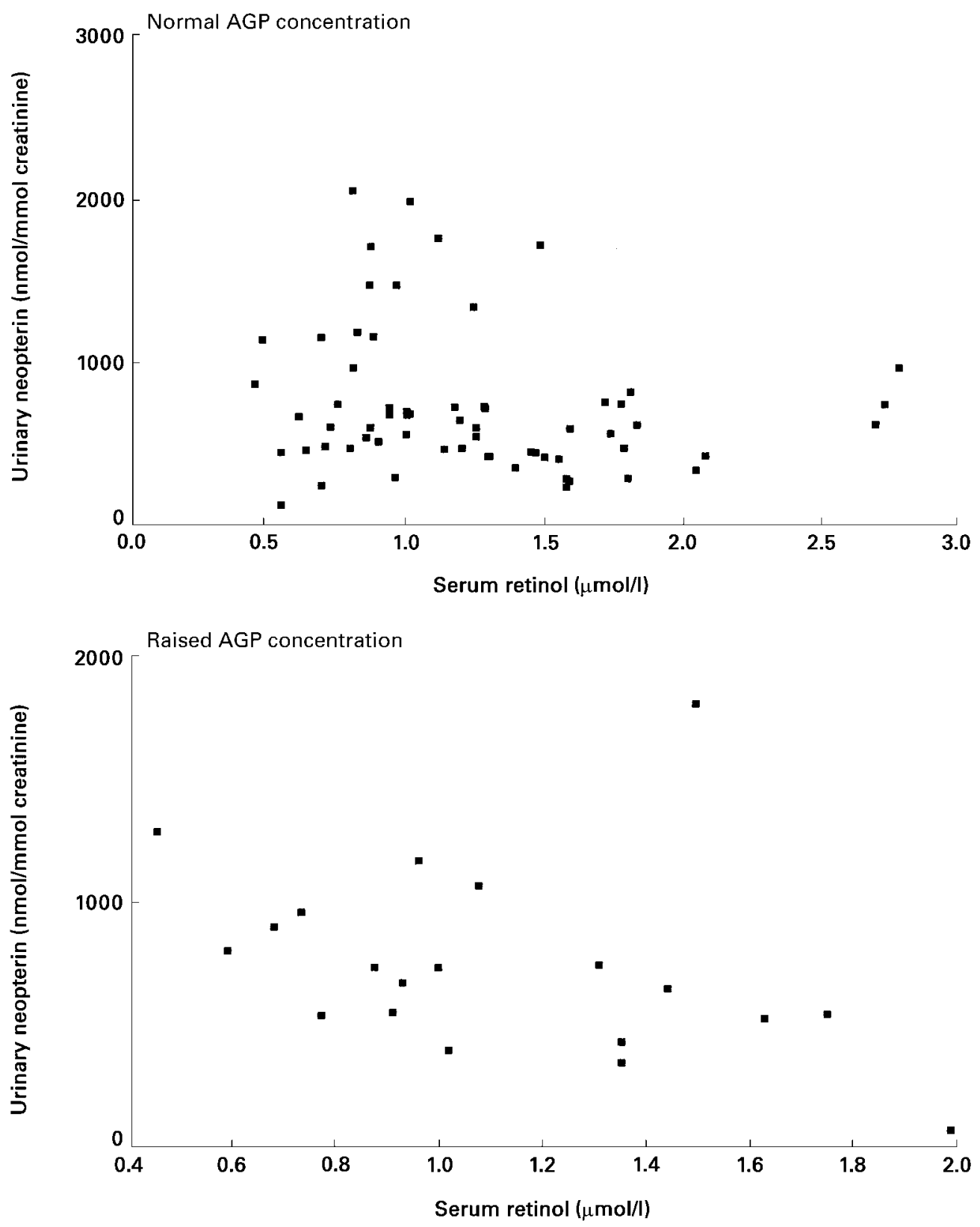

Fig. 1. Relationship between serum retinol and neopterin excretion in children with normal and raised serum $\alpha_{1}$-acid glycoprotein (AGP) concentration. Data are from case and control children at the 3 month follow-up and have been divided into those with AGP $\leq 0.75 \mathrm{~g} / \mathrm{l}$ (normal, $r-0.14, P=0.28, n 64$ ) or AGP $>0.75 \mathrm{~g} / \mathrm{l}$ (raised, $r-0.50, P=0.02, n 20$ ).

highly variable vitamin A status, as indicated by MRDR test results, and widely varying serum retinol, although serum retinol was generally not as low as that of rodents in commonly used models of vitamin A deficiency (Cantorna et al. 1994; Weidermann et al. 1996). However, some limitations of the study need to be mentioned. Most importantly, the study was designed to measure vitamin A metabolism and status, not neopterin, and the sample size may not have been large enough to detect differences between neopterin excretion according to vitamin A status. We had no data on neopterin production by young children from a developing country on which to base sample size calculations initially but our data indicate that many more children would have been needed to determine differences of, say, $20 \%$ between groups. Nevertheless, the sample size was large enough to detect a biologically meaningful difference in production between sick and well children. Furthermore, our data showed no evidence of even a trend towards the increased IFN- $\gamma$ production seen in vitamin A-deficient rodents in several laboratories. Second, for logistical reasons, we measured neopterin rather than IFN- $\gamma$ itself and, although neopterin is considered dependent almost entirely on IFN- $\gamma$-activated monocytes and macrophages (Huber et al. 1984), there remains the possibility that vitamin A deficiency induces some abnormality in the link between IFN- $\gamma$ production and 
macrophage synthesis of neopterin such that excessive IFN$\gamma$ production might not be detectable through measurement of urinary neopterin. Parallel measurement of neopterin and IFN- $\gamma$ production by in vitro-stimulated blood leucocytes of children of known vitamin A status might clarify this. Third, these studies should be repeated in the context of an infectious challenge which might induce considerably higher IFN- $\gamma$ and neopterin production and might involve separate vitamin A-dependent processes. Nevertheless, with these reservations, it seems that some of the rodent and cell culture models which have been used to investigate how vitamin A deficiency impairs resistance to infectious disease may not reflect well the common situation of vitamin A deficiency among children in less-developed countries.

\section{Acknowledgements}

The authors wish to thank Chrissie Mkhasibe for dedicated follow-up of the children, Thoreso Phutheho for driving children for follow-up visits, Rina Naik for conducting HPLC assays, Keith Sullivan for statistical advice, Andrew Tomkins for advice and encouragement, and especially Juana Willumsen for her considerable involvement in the main study. We are grateful to the Wellcome Trust for providing financial support.

\section{References}

Beaton GH, Martorell RJ, Aronson KJ, Edmonston B, McCabe G, Ross AC \& Harvey B (1993) Effectiveness of Vitamin A Supplementation in the Control of Young Child Morbidity and Mortality in Developing Countries. Geneva: United Nations Administrative Committee on Coordination/Subcommittee on Nutrition State of the Art Series Nutrition Policy.

Bowman TA, Goonewardene IM, Pasatiempo AMG, Ross AC \& Taylor CE (1990) Vitamin A deficiency decreases natural killer cell activity and interferon production in rats. Journal of Nutrition 120, 1264-1273.

Cantorna MT, Nashold FE \& Hayes CE (1994) In vitamin A deficiency multiple mechanisms establish a regulatory $\mathrm{T}$ helper cell imbalance with excess Th1 and insufficient Th2 function. Journal of Immunology 152, 1515-1522.

Cantorna MT, Nashold FE \& Hayes CE (1995) Vitamin A deficiency results in a priming environment conducive for Th1 cell development. European Journal of Immunology 25, 1673-1679.

Carmen JA, Pond L, Nashold F, Wassom DL \& Hayes CE (1992) Immunity to Trichinella spiralis infection in vitamin A-deficient mice. Journal of Experimental Medicine 175, 111-120.

Cippitelli M, Ye J, Viggiano V, Sica A, Ghosh P, Gulino A, Santoni A \& Young HA (1996) Retinoic acid-induced transcriptional modulation of the human interferon-gamma promoter. Journal of Biological Chemistry 271, 26783-26793.

De Wet B, van Schalkwyk D, van der Spuy J, du Plessis J, du Toit N \& Burns D (1994) Parrafin (kerosene) poisoning in South Africa - is prevention affordable? South African Medical Journal 84, 735-738.

Filteau SM, Morris SS, Abbott RA, Tomkins AM, Kirkwood BR, Arthur P, Ross DA, Gyapong JO \& Raynes JG (1993) Influence of morbidity on serum retinol of children in a community-based study in northern Ghana. American Journal of Clinical Nutrition 58, 192-197.
Filteau SM, Morris SS, Tomkins AM, Arthur P, Kirkwood BR, Ross DA, Abbott RA \& Gyapong JO (1994) Lack of association between vitamin A status and measures of conjunctival epithelial integrity in young children in northern Ghana. European Journal of Clinical Nutrition 48, 669-677.

Fuchs D, Weiss G, Reibnegger G \& Wachter H (1992) The role of neopterin as a monitor of cellular immune activation in transplantation, inflammatory, infectious, and malignant diseases. Critical Reviews in Clinical Laboratory Sciences 29, 307-341.

Gillespie SH, Dow C, Raynes JG, Berhens RH, Chiodini PL \& McAdam KPWJ (1991) Measurement of acute phase proteins for assessing severity of Plasmodium falciparum malaria. Journal of Clinical Pathology 44, 228-231.

Huber C, Batchelor JR, Fuchs D, Hausen A, Lang A, Niederwieser D, Reibnegger G, Swetly P, Troppmair J \& Wachter H (1984) Immune response-associated production of neopterin: release from macrophages primarily under control of interferon-gamma. Journal of Experimental Medicine 160, 310-316.

Kirkwood BR (1988) Essentials of Medical Statistics. Oxford: Blackwell Scientific Publications.

Iwagaki H, Hizuta A, Tanaka N \& Orita K (1995) Plasma neopterin/C-reactive protein ratio as an adjunct to the assessment of infection and cancer cachexia. Immunological Investigations 24, 479-487.

Ramsden DB, Prince HP, Burr WA, Bradwell AR, Black EG, Evans AE \& Hoffenberg R (1978) The inter-relationship of thyroid hormones, vitamin A and their binding proteins following acute stress. Clinical Endocrinology 8, 109-122.

Rosales FJ, Ritter SJ, Zolfaghari R, Smith JE \& Ross AC (1996) Effects of acute inflammation on plasma retinol, retinol binding protein, and its mRNA in the liver and the kidneys of vitamin A-sufficient rats. Journal of Lipid Research 37, 962-971.

Ross AC \& Stephensen CB (1996) Vitamin A and retinoids in antiviral responses. FASEB Journal 10, 979-985.

Tanumihardjo SA, Permaeshi D, Muherdiyantiningsih Rustan E, Rusmil K, Fatah AC, Wilbur S, Muhilal Katyadi D \& Olson JA (1996) Vitamin A status of Indonesian children infected with Ascaris lumbricoides after dosing with vitamin A supplements and albendazole. Journal of Nutrition 126, 451-457.

Weidermann U, Chen X-J, Enerback L, Hanson LA, Kahu H \& Dahlgren UI (1996) Vitamin A deficiency increases inflammatory responses. Scandanavian Journal of Immunology 44, 578584.

Weidermann U, Hanson LA, Kahu H \& Dahlgren UI (1993) Aberrant T-cell function in vitro and impaired T-cell dependent antibody response in vivo in vitamin A-deficient rats. Immunology 80, 581-586.

Whiteside TL (1994) Cytokine measurements and interpretation of cytokine assays in human disease. Journal of Clinical Immunology 14, 327-339.

Willumsen JF, Simmank K, Filteau SM, Wagstaff LA \& Tomkins AM (1997) Toxic damage to the respiratory epithelium induces acute phase changes in vitamin A metabolism without depleting retinol stores of South African children. Journal of Nutrition 127, 1339-1343.

Wolbach SB \& Howe PR (1925) Tissue changes following deprivation of fat-soluble A vitamin. Journal of Experimental Medicine 42, 753-777.

Zhao Z, Murasko DM \& Ross AC (1994) The role of vitamin A in natural killer cell cytotoxicity, number and activation in the rat. Natural Immunity 13, 29-41.

Zile MH, Bunge EC \& Deluca HF (1981) DNA labeling of rat epithelial tissues in vitamin A deficiency. Journal of Nutrition 111, 777-788. 